SECTION 24. Sociological research.

Savina Natalya Vyacheslavovna

Deputy Director,

Municipal educational institution of the city district Zvenigorod "Training center for the Education sector", Russia

Klyuyeva Inna Viktorovna candidate of technical Sciences, associate Professor of the Department «Designing leather goods», Novosibirsk technological Institute (branch), Moscow State Institute of design and technology

Bekk Natalya Viktorovna doctor of technical Sciences, Professor, head of the Department «Designing leather goods» Novosibirsk technological Institute (branch) Moscow State Institute of design and technology

\title{
SOCIAL AND PSYCHOLOGICAL ADAPTATION OF CHILDREN WITH DISABILITIES AND THEIR INTEGRATION INTO SOCIETY
}

The purpose of this article is to identify the socio-psychological processes of adaptation of disabled children.

Key words: children, adaptation, and society.

\section{СОЦИАЛЬНАЯ И ПСИХОЛОГИЧЕСКАЯ АДАПТАЦИЯ ДЕТЕЙ ИНВАЛИДОВ, И ИХ ИНТЕГРАЦИЯ В ОБЩЕСТВО}

Цель данной статьи заключается в выявлении социальнопсихологических процессов адаптации детей инвалидов.

Ключевые слова: дети, адаптаичя, общество.

Предметом ортопедического снабжения детей с ограниченными возможностями здоровья является выявление возрастных и индивидуальных особенностей развития нижних конечностей с теми или иными патологиями.

Дети с ограниченными возможностями здоровья - это дети, у которых нарушения в развитии представляют им возможность иметь бинефицитарный статус, т.е. позволяют пользоваться социальными льготами и пособиями. По традиционной терминологии таких детей 
раньше называли детьми инвалидами. Сейчас таких детей часто определяют как проблемных.

Первичные нарушения в развитии нижних конечностей приводит к «выпадению» ребенка из социального пространства, нарушению связи с культурой как источником развития высших психических функций, специфических человеческих способностей. По отношению к ребенку с патологиями развития перестают действовать традиционные для каждого возрастного этапа способы и культурные инструменты решения традиционных жизненных задач, рассчитанные на нормальный тип развития. Из-за такого «выпадения» ребенка из традиционного усвоения общественного опыта возникает вторичные отклонения в развитии, социальная некомпетентность. Вследствие этого возникает объективная потребность в «обходных путях», других способах воздействия, т.е. ином, специально организованном пространстве, которое может обеспечить и такому ребенку все необходимые условия «врастания в культуру», реализация своего права на наследование социального и культурного опыта человечества.

Данный предмет изучения не возможен без рассмотрения вопросов психологического и социального аспектов жизни больных детей. Тактика, или установление социально-психологического состояния детей инвалидов, может пониматься в широком и узком смысле. В широком смысле оно сближается с измерением и может относиться к любому объекту, поддающемуся социально-психологическому анализу, выступая как выявление и измерение его свойств. В более узком смысле имеется в виду измерение индивидуальные социально-психологические особенности личности.

В социально-психологическом вопросе выделяют три основных этапа:

1. Сбор данных (беседа с родителями, информация о состоянии ребенка, полученная из других учреждений, изучение медицинской карты, снимков и других данных, результаты обследований).

2. Переработка и интерпретация данных.

3. Составление заключения, определение путей коррекционной и компенсационной помощи и дальнейшего маршрута, как ортопедического направления, так и социально-психологического.

Заключение неразрывно связано с прогнозом и может устанавливаться на разных уровнях.

Первый уровень - симптоматический или эмпирический. На этом уровне заключение ограничивается констатацией особенностей патологий.

Второй уровень - этиологический, учитывающий не только наличие характеристик патологий, но и причины их возникновения. 
Высший уровень - типологический, заключающийся в определении места и значения выявленных характеристике патологий в общей картине жизни ребенка.

В 1989г. Организацией Объединенных Наций был принят текст Конвенции о правах ребенка, которая обладает силой закона. В ней закреплено также право детей с отклонениями в развитии вести полноценную и достойную жизнь в условиях, которые обеспечивают его достоинство, способствуют его уверенности в себе и облегчают его активное участие в жизни общества (ст.23).

Постановлением Правительства РФ от 16 января 1995г. № 59 утверждена Федеральная комплексная программа «Социальная поддержка инвалидов», состоящая из следующих федеральных целевых программ:

- $\quad$ медико-социальная экспертиза и реабилитация инвалидов;

- научное обеспечение и информатизация проблем инвалидности и инвалидов;

- $\quad$ разработка и производство технических средств реабилитации для обеспечения инвалидов (в контексте нашей проблемы имеется ввиду ортопедическое снабжение больных детей).

В целом инвалидность как проблема деятельности ребенка в условиях ограниченной свободы выбора, включает несколько аспектов: правовой; социально-средовой; психологический, общественноидеологический аспект, анатомо-функциональный аспект. Рассмотрим подробнее последний.

Анатомо-функциональный аспект предполагает формирование такой социальной среды (в физическом и психологическом смыслах), которая выполняла бы реабилитационную функцию и способствовала развитию реабилитационного потенциала ребенка инвалида. Таким образом, с учетом современного понимания инвалидности предметом внимания государства при решении этой проблемы должны быть не патологии в организме ребенка, а восстановление его социально-ролевой функции в условиях ограниченной свободы, «выпадению» из социального пространства. Основной аспект при решении проблем инвалидов и инвалидности детей смещается в сторону реабилитации, опирающейся, прежде всего, на социальные механизмы компенсации и адаптации. Таким образом, смысл реабилитации детей инвалидов заключается в комплексном многопрофильном подходе к восстановлению способностей ребенка к бытовой, общественной и профессиональной деятельности (подростки и молодежь) на уровне, соответствующем его физическому, психологическому и социальному потенциалу с учетом особенностей микро- и макросоциального окружения. 
Необходимо также создавать систему комплексной многопрофильной реабилитации, направленную на обеспечение относительно независимой жизнедеятельности детей инвалидов. Крайне важно развитие промышленной основы и подотрасли системы социальной защиты населения, производящей изделия, облегчающие жизнь детей инвалидов. Должен появиться рынок реабилитационных изделий и услуг, определяющих спрос и предложение на них, формирующий здоровую конкуренцию и способствующий адресному удовлетворению потребностей детей инвалидов. Не обойтись без реабилитационной социально-средовой инфраструктуры, способствующей преодолению детьми инвалидами физических и психологических барьеров на путях восстановления связей с окружающим миром.

Таким образом, решение этих задач позволит наполнить содержанием деятельность создаваемых в настоящее время государственных служб медико-социальной экспертизы и реабилитации детей инвалидов.

Оптимальным является устранение или полная компенсация патологии путем проведения восстановительного лечения. Однако это не всегда возможно, и в таких случаях желательно организовать жизнедеятельность больного ребенка таким образом, чтобы исключить влияние на нее существующего анатомического и физиологического дефекта.

В заключение хотелось бы отметить, что для нашей страны проблема оказания помощи детям с патологиями нижних конечностей принадлежит к числу наиболее важных и актуальных, так как рост численности детей инвалидов выступает в качестве устойчивой тенденции нашего социального развития, и пока нет данных, свидетельствующих о стабилизации положения или об изменениях тенденции.

Таким образом, мы приходим к итоговому выводу, что социальная реабилитация и адресное ортопедическое удовлетворение потребностей детей инвалидов с патологиями нижних конечностей является восстановлением способностей к социальному функционированию. 